\title{
Eosinophilic granuloma of the spine involving $\mathrm{C} 1$ and pulmonary infiltration in young children - Presentation of two cases with a follow-up over 10 years including review of the literature
}

\author{
Tugrul Kocak, $\mathrm{MD}^{\mathrm{a}, *}$, Benjamin Ulmar, $\mathrm{MD}^{\mathrm{b}}$, Heiko Reichel, $\mathrm{MD}^{\mathrm{a}}$, Sebastian Weckbach, $\mathrm{MD}^{\mathrm{a}}$

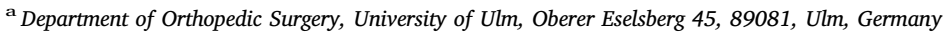 \\ ${ }^{\mathrm{b}}$ Neuenbürg Hospital, Marxzeller Str. 46, 75305, Neuenbürg, Germany
}

\section{A R T I C L E I N F O}

\section{Keywords:}

Eosinophilic granuloma

Children

Spine

Atlas

Chemotherapy

\begin{abstract}
A B S T R A C T
Objectives: The incidence of spinal eosinophilic granuloma in children is low.

Methods: Clinical case presentation of two children ( $q 18$ months old, $\sigma^{\prime} 16$ months old) complaining of acute torticollis. Follow-up period was 11 years in the female patient and 13 years in the male patient.

Results: The diagnostics certified a spinal eosinophilic granuloma: the girl had a multilevel spinal disease including the atlas, the boy a thoracic and pulmonary manifestation. Both were treated with chemotherapy with good clinical results.

Conclusions: Overall, the above described is a very rare clinical entity. However, persisting torticollis in children should be clearly diagnosed.
\end{abstract}

\section{Introduction}

The eosinophilic granuloma is a rare tumor, the incidence is approximately 1:1.500.000 people. ${ }^{1}$ It is one of the three described manifestations of the Langerhans cell histiocytosis (LCH). The two other forms are the Letterer-Siwe disease and the Hand-Schüller-Christian disease. These three disease manifestations show the same disorder process - a clonal proliferation of Langerhans cells. ${ }^{2,3}$ Langerhans histiocytes are dentritic cells which present antigens. They are usually found isolated in the epidermis and in a small number throughout the whole body. Letterer-Siwe disease is the most malignant form: Disseminated clusters of Langerhans cells are found throughout the body. Hand-Christian-Schüller disease classically presents with the clinical triad of scull lesion, exophthalmus and diabetes insipidus. The eosinophilic granuloma is a benign proliferation of Langerhans cells occurring in a multifocal manner that commonly affects the skeleton. ${ }^{4}$ The most typical manifestations are the skull, femur, ribs, pelvis and the spine. At the spine, the thoracic level is most commonly affected, followed by the lumbar and cervical spine. ${ }^{2,5} 90 \%$ of the patients are between 5 and 15 years old. ${ }^{4}$ In $79 \%$ of eosinophilic granulomas, the disease is solitary, in about $7 \%$ a multifocal manifestation are described, and $14 \%$ belong to other forms of the disease. ${ }^{6}$ The clinical course of children with a cervical manifestation of eosinophilic granuloma is quite variable. Affected children normally present with an acute onset of neck pain, a reactive torticollis and stiffness without history of trauma. ${ }^{7-10}$ Denaro et al. ${ }^{8}$ reported an incidence of torticollis in $71 \%$ of their 7 pediatric patients with an eosinophilic granuloma of the cervical spine.

\section{Patients and methods}

In August 2004, one girl (18 months old) and one boy (16 months old) were referred to our outpatient clinic. The girl complained of torticollis since 10 days after a slight trauma and an upper air way infection. The boy had a history of spontaneous neck pain and torticollis of about 2 weeks. No trauma or infection in the previous history could be detected.

The physical evaluation showed in both patients no neurological deficits, body temperature was normal. Both patients showed tenderness of the upper cervical spine and a right lateral tilt of their head with a minimal rotation to the left.

In both children, white blood cell account was normal and further laboratory investigation showed a slightly elevated CRP and cell sedimentation rate.

Plain radiographs showed a mild head and neck tilt. Further diagnostic work-up was started in both children in mild sedation.

In the female patient, computed tomography (CT) (Fig. 1) and

\footnotetext{
* Corresponding author.

E-mail addresses: tugrul.kocak@rku.de (T. Kocak), benjamin.ulmar@gmx.de (B. Ulmar), heiko.reichel@rku.de (H. Reichel), sebastian.weckbach@rku.de (S. Weckbach).
} 


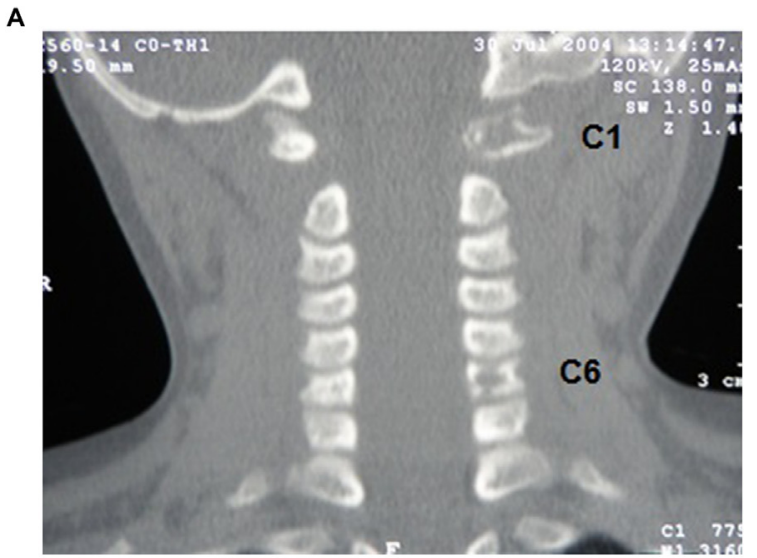

B

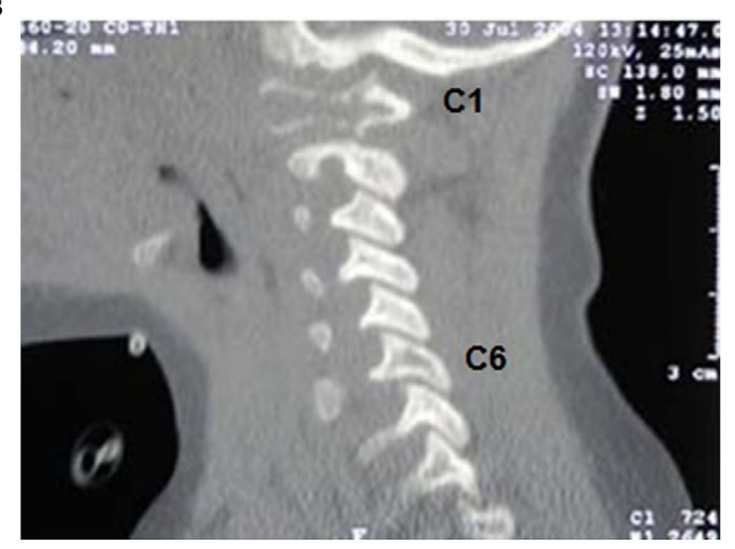

C

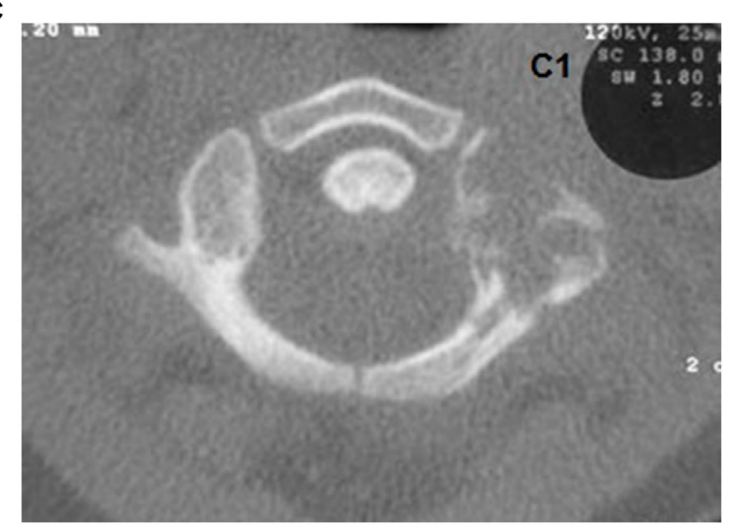

Fig. 1. a, b, c. CT scans of the cervical spine of the female patient: Lytic lesions of the left lateral mass of the atlas (C1) and the sixth cervical vertebra (C6).

magnetic resonance tomography (MRI) (Fig. 2) showed a lytic lesion in the left lateral mass of the atlas (C1), the sixth cervical vertebra (C6) and the seventh thoracic vertebra (T7). No additional soft tissue was involved. No instable fracture but a characteristical vertebra plana could be diagnosed at the level of T7. CT and MRI did not show skeletal lesions of the skull, ribs and the lumbar spine. A visceral co-affection could also be excluded via CT.

In the male patient, CT of the cervical and thoracic spine and the thorax revealed a lysis of left portion of the third thoracic vertebra (T3) and a pulmonary infiltration of the right second segment (Fig. 3). MRI of the complete spine and skull showed a classical vertebra plana at the level of T3 leading to a hyperkyphosis and left-lateral scoliosis of the upper spine (Fig. 4).

No additional bony lesions could be observed. At the level of T3 the intervertebral discs were not affected. Paravertebral, the adjacent soft
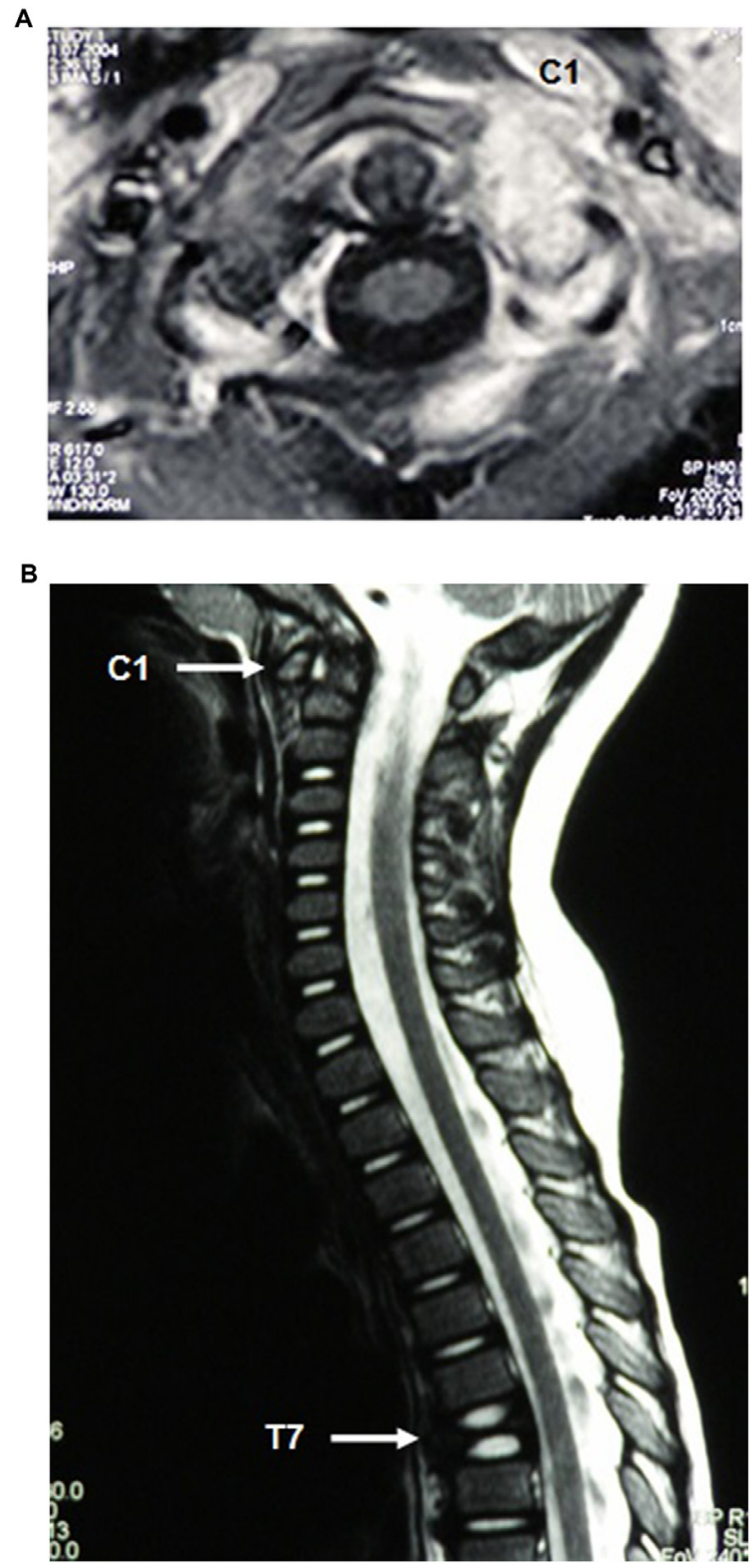

Fig. 2. a. MRI of the atlas (C1) of the female patient showed a lytic lesion of the left lateral mass. b. MRI of the female patient showed fluid between the dens axis (C2) and the anterior arch of the atlas (C1). The seventh thoracic vertebra (T7) is shown as a classical vertebra plana.

tissues were not sharply defined and the anterior ligament was elevated. The myelon was not compromised or infiltrated.

\section{Results}

To verify the diagnosis of eosinophilic granulomas and to exclude other diagnosis like Ewing sarcoma, osteosarcoma or infection, biopsy was performed in both patients. The female patient was biopsied at the first and sixth cervical vertebras, the male patient at the third thoracic vertebra. In both cases the histological investigation showed proliferated cells with eccentrically located round or oval nuclei and eosinophilic cytoplasm, corresponding to clons of Langerhans cells in a granulomatous tissue. The diagnosis of eosinophilic granuloma could be clarified and both children were treated with chemotherapy.

After referring the children back to the pediatric department, both were treated following the LCH III International Study Protocol for patients with Langerhans Cell Histiocytosis and "Multifocal Bone 


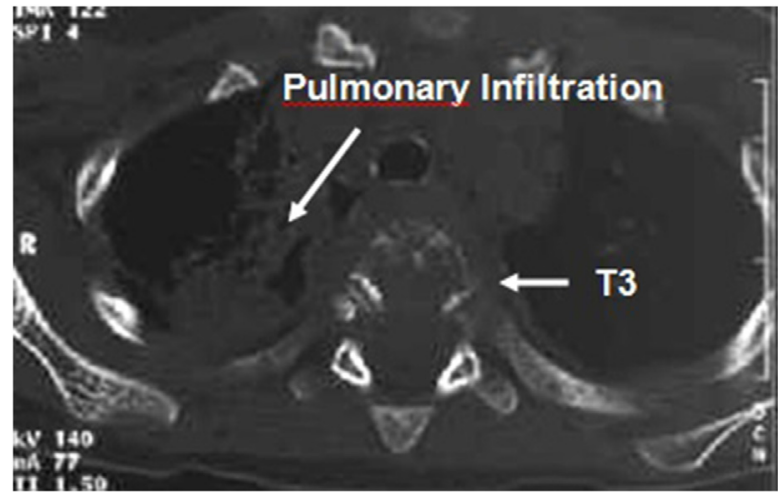

Fig. 3. CT of the male patient showing a lytic destruction of the third thoracic vertebra (T3) with involvement of the adjacent soft tissue and osteolysis of the left pedicle. In the scans the pulmonary infiltration in right second segment can also be observed.

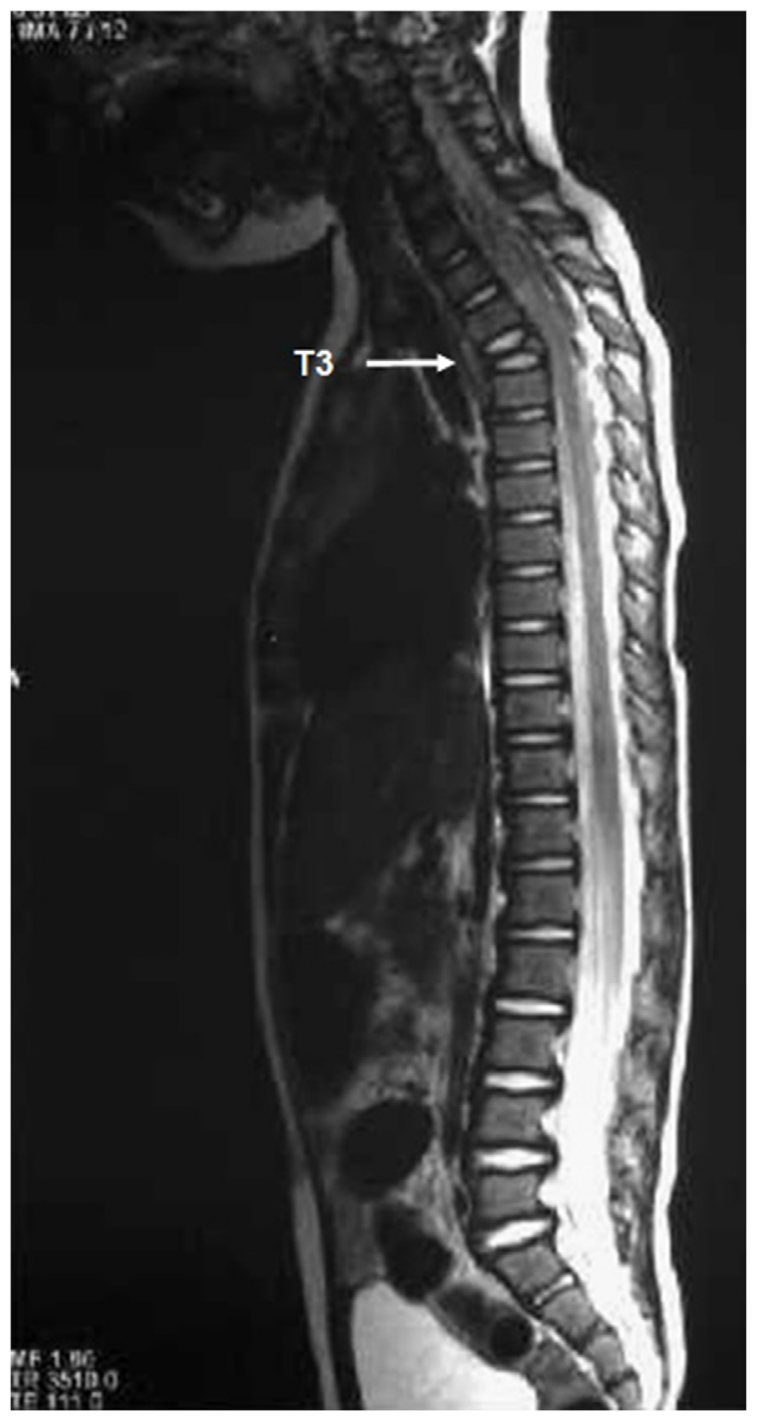

Fig. 4. MRI of the complete spine of the boy with a vertebra plana at the level of the third thoracic vertebra (T3).

Diseases and Special Site Involvement". ${ }^{11}$ The treatment protocol includes vinblastin $\left(6 \mathrm{mg} / \mathrm{m}^{2}\right)$ as intravenous bolus at day 1 of the week for 6 weeks and oral prednisone $\left(40 \mathrm{mg} / \mathrm{m}^{2} /\right.$ day) continuously for 28 days and than stepwise reduction over 2 weeks. Both children got the

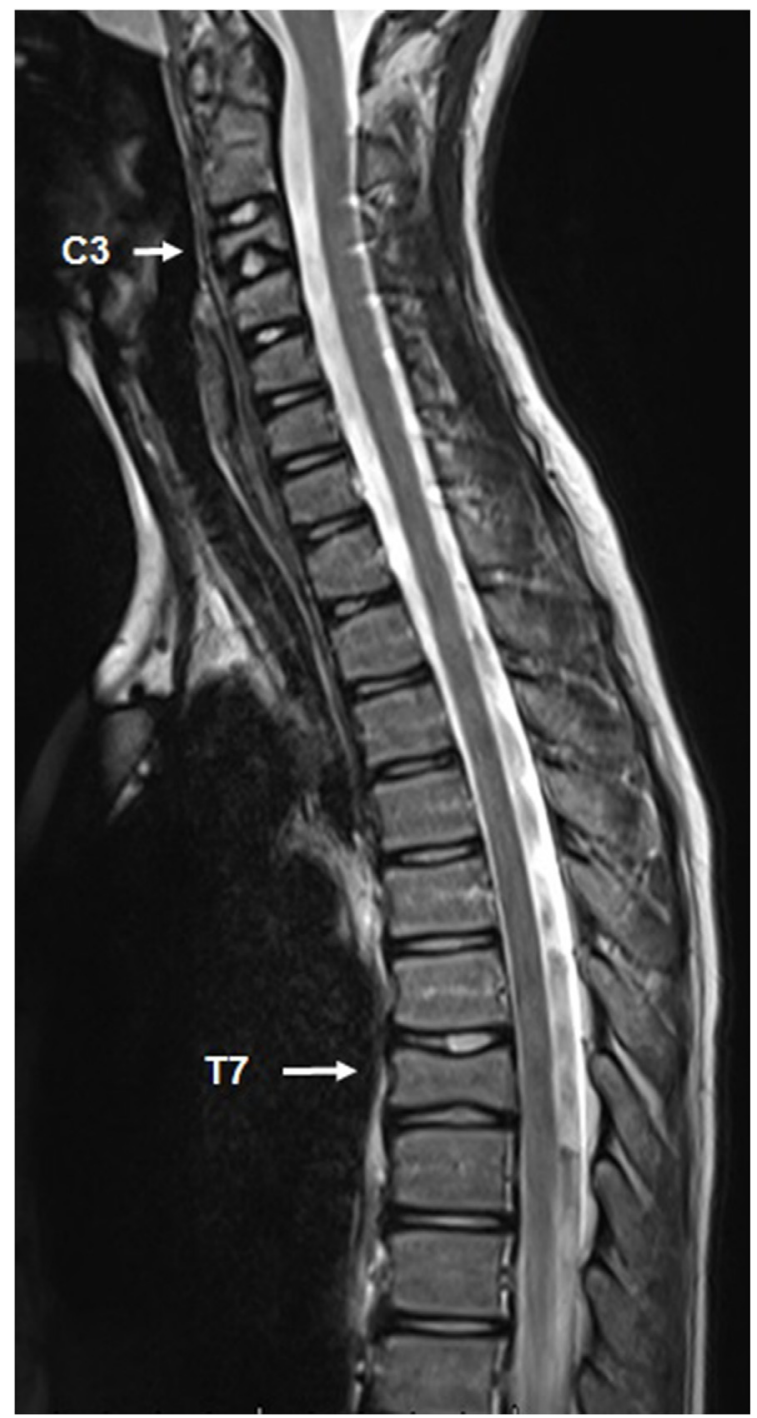

Fig. 5. MRI of the cervical and thoracic spine of the girl with stable situation due to T7. The atlas (C1) and C6 come regularly to the presentation. New, but healed fracture of $\mathrm{C} 3$.

following therapy circle for the next 25 weeks with intravenous application of vinblastin $6 \mathrm{mg} / \mathrm{m}^{2}$ once a week and oral prednisone $40 \mathrm{mg}$ / $\mathrm{m}^{2}$ /day on days $1-5 /$ week.

In both children symptoms decreased, and they were free of pain and of neurological deficits. Both patients remained under care in the pediatric department for several years.

In the female patient, last MRI of the spine was performed after 11 years (Fig. 5). There were no pathological findings referring formerly affected vertebras $\mathrm{C} 1$ and $\mathrm{C} 6$. In addition, stable bony structures were found in T7. However, diagnosed was an old fracture of C3.

Within the clinical examination, the girl was painless and normal neurological status was ascertained.

In the male patient, last MRI of the spine was done after 13 years (Fig. 6). By that time, the former affected vertebra T3 showed almost complete restoration. There was no more pulmonary manifestation.

The patient was also free of pain and of neurological disturbances.

\section{Discussion}

The eosinophilic granuloma is a tumor of the child or young adolescent. $80 \%$ of the patients are younger than 10 years old. ${ }^{12}$ The gender distribution (female to male) in children is $1: 1.7 .^{7}$ The typical 


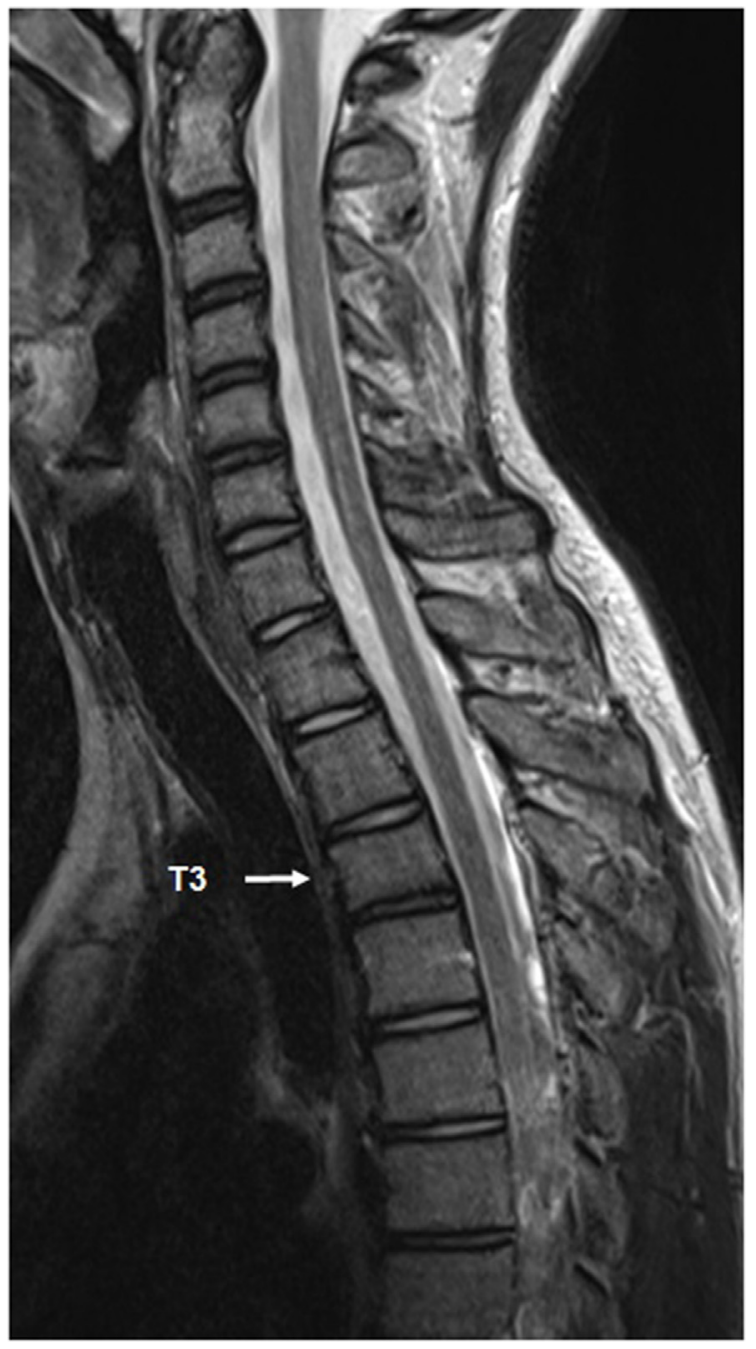

Fig. 6. MRI of the cervical and thoracic spine of the boy with almost complete restoration of the previous concerned T3 vertebra. Pulmonary affection was exluded.

clinical picture of the affected cervical spine is an acute torticollis combined with a restricted range of motion or neck pain.

In a review, Bertram et al. reported these symptoms in $76 \%$ and neurological symptoms in $33 \% .^{7}$ In comparison, Denaro et al. ${ }^{8}$ described pain in $100 \%$, torticollis in $71 \%$, and neurological deficits in $29 \%$ of their 7 pediatric patients.

The manifestation of an eosinophilic granuloma at the cervical spine is rare. In a meta-analysis, Bertram et al. reported in 2002 only 53 cases worldwide, 10 involving adults, 43 children. $^{7}$ In 2004, Garg et al. ${ }^{3}$ added 11 cases and Tan et al. ${ }^{13} 4$ additional cases in children.

Simanski et al. ${ }^{14}$ and Ngu et al. ${ }^{2}$ reported also in 2004 a cervical involvement in two case reports about one adult ${ }^{14}$ and one child. ${ }^{2}$ In 2008, Denaro et al. ${ }^{8}$ described 7 cases of pediatric cervical spine affection. In the following years, less articles about eosinophilic granuloma of the pediatric cervical spine with one, ${ }^{9}$ two ${ }^{5}$ and $4^{10}$ patients were published.

A multilevel spinal manifestation is described in about $11 \%,{ }^{7}$ an additional extrasceletal manifestation in about $8 \% .^{3}$ According to Bertram et al., C3-5 are involved in 60\%. ${ }^{7}$ Until now, there have been only less than 10 cases published, describing an eosinophilic granuloma of the first vertebra in children and furthermore with a follow-up over 10 years. $^{2,3,} 15-18$ The spinal eosinophilic granuloma commonly affects the vertebral bodies, but it usually spares the posterior elements.

Since eosinophilic granulomas show a variety of clinical presentations, there are several treatment options leading to a good outcome. ${ }^{7}$ These options include observation, prolongated immobilisation, ${ }^{8,10}$ chemotherapy, ${ }^{7}$ curettage with or without bone grafting and/or stabilization, ${ }^{2,4,5}, 8-10$ corticosteroid injection, ${ }^{13,19}$ and low dose radiation therapy. ${ }^{4,10}$ With regard to the different treatment options, a biopsy should confirm the diagnosis. ${ }^{2,4,8,10,13,19,20}$ Due to small case numbers, there are no randomized, prospective studies evaluating the efficiency of different treatment methods.

Nevertheless, several treatment suggestions have been made. Surgical treatment is recommended in spinal instability or neurological deficits. $^{2,4,5,8,20}$ Symptomatic lesions that have not compromised the spinal cord could be treated by excessive curettage with or without bone grafting and/or stabilization. ${ }^{2,4,8,9}$ Capanna et al. ${ }^{19}$ and Tan et al. ${ }^{13}$ reported the intra-lesional injection of corticosteroids. Finally, the use of systemic chemotherapy is recommended in eosinophilic granulomas with multilevel spinal involvement and/or additional visceral manifestation. ${ }^{2,10,11}$

Therefore, our patients were treated with systemic chemotherapy using vinblastin and prednisone ${ }^{11}$ and have shown a good response.

\section{References}

1. Nyholm K. Eosinophilic xanthomatous granulomatosis and Letterer-Siwe`s disease. Acta Pathol Microbiol Scand. 1971;216(suppl 1) 1+.

2. Ngu BB, Khanna AJ, Pak SS, McCarthy EF, Sponseller PD. Eosinophilic granuloma of the atlas presenting as torticollis in a child. Spine. 2004;29(5):E98-E100.

3. Garg S, Mehta S, Dormans JP. Langerhans cell histiocytosis of the spine in children. $J$. Bone Joint Surg. Am. 2004;86-A(8):1740-1750.

4. McCarthy EF, Frassica FJ. Pathology of Bone and Joint Disorders with Clinical and Radiographic Correlation. 1998; 1998 Philadelphia, PA.

5. Li J, Lü GH, Wang B, Wang XB, Lu C, Kang YJ. Pedicle screw implantation in the thoracic and lumbar spine of 1-4-year-old children: evaluating the safety and accuracy by a computer tomography follow-up. J Spinal Disord Tech. 2013;26(2):E46-E52.

6. Schajowicz F. Tumors and Tumorlike Lesions of Bone and Joints. 1981; 1981 New York, Heidelberg, Berlin.

7. Bertram C, Madert J, Eggers C. Eosinophilic granuloma of the cervical spine. Spine. 2002;27(13):1408-1413.

8. Denaro L, Longo UG, Papalia R, Di Martino A, Maffulli N, Denaro V. Eosinophilic granuloma of the pediatric cervical spine. Spine. 2008;33(24):E936-E941.

9. Akhaddar A, Boucetta M. Eosinophilic granuloma of the cervical spine manifesting as torticollis in a child. Pan. Afr. Med. J. 2014;19:36.

10. Menezes AH, Ahmed R. Primary atlantoaxial bone tumors in children: management strategies and long-term follow-up. J Neurosurg Pediatr. 2014;13(3):260-272.

11. Minkov M, Gadner H. Treatment protocol of the third international study for Langerhans cell histiocytosis. https://clinicaltrials.gov/ct2/show/NCT00488605; 2001, Accessed date: 5 November 2017.

12. Scarpinati M, Artico M, Artizzu S. Spinal cord compression by eosinophilic granuloma of the spine. Case report and review of the literature. Neurosurg Rev. 1995;18(3):209-212

13. Tan G, Samson I, De Wever I, Goffin J, Demaerel P, Van Gool SW. Langerhans cell histiocytosis of the cervical spine: a single institution experience in four patients. $J$ Pediatr Orthop B. 2004;13(2):123-126.

14. Simanski C, Bouillon B, Brockmann M, Tiling T. The Langerhans' cell histiocytosis (eosinophilic granuloma) of cervical spine: a rare diagnosis of the cervical pain. Magn Reson Imaging. 2004;22(4):589-594.

15. Barber FA, Roach JW. Torticollis: a presentation of eosinophilic granuloma. A case report. Orthopedics. 1986;9(9):1237-1239.

16. Couchot J, Cart P, Pavec E, Lefort G. Iconographic rubric. Eosinophilic granuloma of the anterior arch and of the left lateral mass of C1. Arch Fr Pediatr. 1991;48(3):215-216.

17. Davidson RI, Shillito Jr J. Eosinophilic granuloma of the cervical spine in children. Pediatrics. 1970;45(5):746-752.

18. Hardy JR, Pouliquen JC, Pennecot GF. Posterior arthrodesis of the upper cervical spine in children and adolescents. Apropos of 19 cases. Rev Chir Orthop Reparatrice Appar Mot. 1985;71(3):153-166.

19. Capanna R, Springfield DS, Ruggieri P, et al. Direct cortisone injection in eosinophilic granuloma of bone: a preliminary report on 11 patients. J Pediatr Orthop. 1985;5(3):339-342.

20. Green NE, Robertson Jr WW, Kilroy AW. Eosinophilic granuloma of the spine with associated neural deficit. Report of three cases. J. Bone Joint Surg. Am. 1980;62(7):1198-1202. 